\title{
RESPONSIBILITY CENTER BUDGETING AS A MECHANISM TO DEAL WITH ACADEMIC MORAL HAZARD
}

\author{
GORDON M. MYERS \\ SIMON FRASER UNIVERSITY
}

\begin{abstract}
Universities face inherent informational asymmetries. These make university budgeting prone to various challenges including moral hazard. The last forty years has seen some large research- intensive universities move from centralized incremental budgeting to decentralized Responsibility Center Budgeting (RCB). It is assumed that a faculty chooses a level of costly effort in generating revenue for the university. The level of faculty effort is not observable by the central administration. When there is no revenue uncertainty or when the faculty is not risk averse, pure RCB is best from the perspective of the administration. The intuition is that pure RCB fully aligns financial responsibility with academic authority, that is, it makes the faculty the residual claimant. Once the faculty is risk averse, partial RCB is optimal. Partial RCB provides a balance between providing the right incentives to the faculty and the university reducing the revenue risk faced by the faculty.
\end{abstract}

Keywords: university governance, Responsibility Center Budgeting (RCB), mechanism design, moral hazard

\section{Résumé}

Les universités sont confrontées à des asymétries d'information importantes. Celles-ci rendent la budgétisation des universités sujette à plusieurs défis, notamment le risque moral. Au cours des quarante dernières années, certaines grandes universités à forte intensité de recherche sont passées d'une budgétisation incrémentale centralisée à une budgétisation décentralisée par centres de responsabilité (BCR). On suppose que pour générer des revenus pour l'université, une faculté universitaire choisit un niveau d'effort qui lui est coûteux mais qui n'est pas observable par l'administration centrale. En l'absence d'incertitude par rapport aux revenus, ou lorsque les facultés ne sont pas réticentes au risque, la BCR pure est préférable du point de vue de l'administration centrale. L'intuition est qu'une BCR pure aligne complètement la responsabilité financière avec l'autorité universitaire, et ceci parce que la faculté devient l'ayant droit résiduel. Lorsque les facultés ont une aversion au risque, la BCR partielle est optimale. La BCR partielle offre alors à une université un équilibre entre les incitations qu'elle crée et le risque encouru par les facultés par rapport aux revenus générés.

Mots-clés : gouvernance des universités, budgétisation décentralisée par centres de responsabilité (BCR), conception des mécanismes, risque moral

\section{Introduction}

The original partitioning of universities by academic discipline in the late 19th century was connected to the inability of any one person to accurately evaluate teaching and research across the breadth of the university (see Cole (2011)). That decentralization of academic authority was not matched by a decentralization of financial responsibility. The traditional approach to university budgeting was incremental budgeting, a centralized top-down approach characterized by central control of all unrestricted reve- nue. Budget discussions between the central administration (Provost, President, CFO, henceforth, the administration) and a faculty Dean (henceforth, the faculty) begin with the previous year's budget and then move away from that with incremental adjustments for new developments such as expenditure on a new faculty position.

Incremental budgeting has strengths, but a difficulty with this centralized approach is that doing it well places enormous informational demands on the administration. In incremental budgeting the difference between projected revenues and costs generate an expected pool of 
resources available for incremental adjustments. Faculties make cases for resources in a system where there is no clear downside to requesting more. As a result, the pool is oversubscribed and must be rationed among incremental requests. For the administration to make the economically efficient allocation of those scarce resources requires an intimate knowledge of departments as diverse as Physics, Economics, Engineering, and Music. Given this severe information problem, it is unsurprising that long run incremental budgeting tends to maintain initial faculty budget shares. ${ }^{1}$

As pointed out by Lang (2002),

In large, complex institutions like the University of Toronto, the president and his administration had the authority to make specific decisions about the allocation of resources to colleges and faculties but sometimes did not have the requisite sapience (March, 1994) or proximity (Whalen, 1991) to do so because crucial plans and budgets were often divorced from the reality of scholarship and program delivery. (p. 127)

In other words, it is the same asymmetric information problems that led to the decentralization of academic authority that make centralized budgeting problematic. The reality is that professors at the state of the art in their discipline must do the teaching and research. That work requires local knowledge, effort, compromise and tradeoffs. Under incremental budgeting the administration would try to monitor and provide oversight on expenditures but monitoring of that teaching and research effort is very difficult, if not impossible, because of a lack of intellectual proximity. For example, central officers who are not from a particular discipline, cannot determine the appropriate curriculum, appropriate class-size, or required student performance standard (i.e. retention rate) for a state-of-the-art course in that discipline. The administration could devote a great deal of time and resources to find out, but in a year or two, that knowledge would be obsolete.

As usual the asymmetric information maps directly into moral hazard, that is, hidden action which is a serious difficulty for any centralized budgeting approach. For example, when the head of an academic unit tells the administration that the appropriate curriculum in their discipline necessitates very small classes of very strong students, the administration/Provost, when not a professor from that discipline, does not know whether that is true. It may simply be that the faculty does not want the reduction in research time necessitated by teaching larger classes of challenging students.

Responsibility Center Budgeting (RCB) is an alternative decentralized approach. It has a history going back over 40 years with early adopters being Harvard, the University of Pennsylvania, and the University of Southern California. Of universities currently employing RCB in Canada, the first to adopt a full RCB approach was the University of Toronto. It experimented with an RCB-type model at its Scarborough campus from 1997 and then went to a full model, in 2005-06. McMaster and Queen's University followed suit in the 2013-14 period (see Deering and Sá, 2014). UBC implemented a model where faculties are partially paid by the revenue they generate in 2010. SFU began experimenting in 2011 and implemented a partial RCB in 2016-17.

Unlike incremental budgeting, which is cost based, $\mathrm{RCB}$ is both cost and revenue based. In its pure form it assigns all revenue directly to faculties and then assigns both direct costs (e.g. faculty salaries) and indirect costs (e.g. facility costs) to the faculties generating those costs. Resources can be moved to the center for strategic or public good or overhead related expenditures and to redistribute resources across faculties through "taxation" of revenues. ${ }^{2}$

A central element of the logic behind the RCB approach is to face faculties with the university's financial problem (i.e. the budget constraint). From an economics perspective, this allows aligned decentralization of decision-making authority to the faculty level, where the faculty makes the academic decision but faces the university's financial realities. This alignment deals directly with the asymmetric information problem discussed above. For example, the faculty chooses the effort to devote to research versus the effort to devote to revenue generation, but now while facing the full financial consequences of those choices.

For a review of the literature on Responsibility Center Management see Chapter 4 of Curry, Laws, and Strauss (2013). There is much written about the logic behind RCB, implementation experience, and the historical assessment of its performance (e.g. Curry, Laws, \& Strauss, 2013; Jaquette, Kramer, \& Curs, 2018; Priest, Becker, Housler, \& St. John, 2002; Whalen, 1991). The logic is summarized by the management maxims provided by Whalen (1991) in chapter 2 and Curry, Laws, and Strauss (2013, p. 51). For implementation experience, 
see for example, Strauss and Curry (2002). For an evaluation of strengths and weaknesses of centralized budget models versus RCB see Chapter 1 of Curry, Laws, and Strauss (2013) and for university RCB cases, see Chapters 5 and 6 of Curry, Laws, and Strauss (2013), and Deering and Sá (2014).

Massey (2016) provides an interesting economic analysis of universities, including budgeting, but is not about RCB. Wilson (2002) gives an economic analysis of RCB focusing on how RCB could be expected to lead to imperfect internal markets and inefficiency once market failures such as monopolies, externalities, and public goods are considered. The present paper takes a different approach. Arguably, the primary source of economic inefficiency in markets is asymmetric information leading to the problems of moral hazard/hidden action and adverse selection/hidden type. The mechanism design literature is about the design of mechanisms to deal with asymmetric information. This paper will formally model RCB as a mechanism designed to overcome the informational asymmetries inherent in university management. It is hoped that the paper can fill in one or two important pieces in our understanding of RCB.

There are a set of unanswered questions and unexplained empirical regularities in the existing literature. Given that RCB decentralizes financial authority and university leaders typically believe in their ability to lead, how is it that a central administration would ever prefer RCB over a centralized approach? Second, does the rationale for RCB-of aligning authority and financial responsibility-hold up under a formal mechanism design analysis? As noted by Deering and Lang (2017), the attraction of RCB is multifaceted: it promised to promote the generation of revenue; improve the delivery of support services; and reduce costs in research and the education programs. Given this promise, the third question presents itself. Why has the adoption of an RCB approach not been more widespread? Is it simply the "slow university" or is there more to it? Further, why are almost all RCB implementations partial (see Deering \&Lang 2017) and why have there been a number of pull backs from pure RCB (Curry, Laws, \& Strauss, 2013, p. 123)? In Canada, the first university to adopt RCB was the University of Lethbridge in 1993-94. It reverted to incremental budgeting a decade later. Curry, Laws, and Strauss (2013) provides a list of American universities using RCB as of 2013 and Zisken (2014) has a list for North America. Consideration of the lists leads to the obvious empirical regularity and a final question as to why RCB is more apt to be employed at very large, good, and complex universities (see also Curry, Laws, \& Strauss, 2013, p. 123). ${ }^{3}$

In the next section of the paper, I lay out the model informally and in the third section I present the results, including possible answers to the questions, and intuition for the results. In Appendix 1, I provide the formal mathematical model and in Appendix 2 (available upon request), I extend the model and qualitative results to the case where the expenditure has a public goods nature.

\section{An Exposition of the Model}

Mechanism design problems help us think about systems where a principal wants to induce an agent or subordinate to take some action(s) to advance the interests of the principal. ${ }^{4}$ In Appendix 1, I build a formal model where a faculty (the agent) chooses a level of costly effort in generating revenue for the university. It could be effort on the recruitment of students, retention of students, and enrollment planning and preparation. ${ }^{5}$ The cost of the revenue-generating effort can have a number of interpretations, but the focus here is the cost of forgone leisure or foregone research time/effort.

Due to a lack of intellectual proximity, the action, that is the effort level, cannot be directly monitored by the administration. These faculty efforts through student tuition and government funding for students, generate operating revenue for the university. The revenue is assumed deployed in the research and teaching missions. ${ }^{6}$ The administration (the principal) chooses among alternative budgeting approaches from incremental through a continuum to pure RCB to induce the faculty to choose the "right" level of effort from the administration's perspective in the face of asymmetric information and hidden effort.

There are always random events and therefore uncertainty in university budgeting. I assume that the revenue generated by the faculty depends on faculty effort, but also on luck or other uncertain factors beyond faculty control. The uncertainty is a characteristic of the environment. For example, exchange rate uncertainty, when a university is dependent on international student tuition revenue. I also assume that the administration and faculty are not risk loving. In other words, a faculty prefers a certain budget of $\$ 500 \mathrm{~K}$ over $\$ 1$ million or $\$ 0$ based on the flip of a fair coin. A faculty likes a larger budget but does not like risk, that is, variance in its budget.

The effort made by the faculty cannot be observed 
by the administration and so cannot be used in a budget agreement or rule between the administration and faculty because it is not mutually verifiable. It is assumed that the budget rule is instead written on the resultant revenue which is observed by both and which does provide an imperfect signal of the effort used to generate it. It is an imperfect signal because of the uncertainty inherent in the environment. Let $y$ be the amount of revenue generated (some number of dollars) and let the payment from the administration to the faculty consist of two parts. First, $a$ a fixed dollar payment to the faculty. Second, $b$ a share of the revenue generated. Then the total payment to the faculty is $a+b y$. This is the mechanism designed to deal with the hidden effort. Even though this very simple linear form is restrictive, it does provide sufficient flexibility to allow an analysis of incremental budgeting, pure RCB, and intermediate cases. For example, if $b=0$ and $a>0$ then we have the incremental budgeting case where one-hundred percent of the revenues generated flow to the central administration and faculty budgets are generated by fixed payments from the administration to the faculty to cover particular expenditures determined by the central administration and the faculty. At the other extreme of $b=1$, we have a pure RCB with one-hundred percent of the revenue flowing directly to the faculty and then fixed payments flowing back to the administration $(a<0)$ to cover, for example, central support services and/ or cross subsidies of other faculties (subvention). With $0<b<1$ we have the intermediate case, which I label partial RCB.

Potentially, there are many types of "tax" instruments that could be used in the mechanism, for example, lumpsum taxes (our $a$ ), proportional taxes on revenue (our $b$ ), or progressive taxes on revenue (i.e. a marginal tax rate on revenue increasing in revenue). Once there is more than one type of tax there will be an important distinction between who receives the revenue generated (determined by $b$ ) and who spends the revenue (determined by both $b$ and the fixed payment, $a$ ). For example, if $a$ is a large negative (so that the administration takes a large fixed sum of money from the faculty) and $b=1$ (faculties are able to keep every dollar of revenue above $a$ ), then much of the revenue is spent by the administration even though it is pure RCB. I define RCB by who receives the revenue generated (i.e. b) and who is thereby facing the revenue risk. ${ }^{7}$

The budget for the faculty is then $a+b y$ where $y$, the revenue, depends on their revenue raising efforts. The risk averse faculty wants a large stable budget and low revenue-raising effort costs (see $\left(O^{F}\right)$ in Appendix 1 ). The budget for the administration is (1-b)y- $a$ and it also wants a large and stable budget (see $\left(O^{4}\right)$ in Appendix 1$){ }^{8}$ The budget model ( $a$ and $b$ ) is chosen by the administration so that it is sufficiently in the faculty's interest that the faculty is onside, for example, so that it is possible to hire and retain a Dean for the faculty (see the participation constraint $[\mathrm{PC}]$ ). The budget model is also chosen to make the administration's preferred effort level, the faculty's preferred choice (see the incentive compatibility constraint [ICC]). ${ }^{9}$

In the model, the university's administration chooses the budget model ( $a$ and $b$ ) to achieve its objective as best as possible given these constraints. Facing the budget model, the faculty then makes its choice of effort to achieve its objectives. In the appendix, I show this leads to the administration's preferred budgeting rule:

$$
b^{*}=\frac{1+r^{U} c \sigma^{2}}{1+\left(r^{F}+r^{U}\right) c \sigma^{2}}
$$

Where $r^{F}$ and $r^{u}$ measure the degree of risk aversion of the faculty and the administration respectively (zero would be risk neutrality), c measures how quickly the cost of the effort increases with effort, and $\sigma^{2}$ measures the degree of variability/uncertainty in the revenue environment. As above, $b^{*}=1$ is pure RCB and $b^{*}=0$ is incremental budgeting.

Through a consideration of small, one at a time changes in $r^{F}, r^{U}, c$, and $\sigma^{2}$ on $b^{*}$, one can verify that the administration would want to move further away from pure RCB, that is a lower $b^{*}$, the more uncertain the environment, the more quickly the costs of effort increase with effort, the more risk averse the faculty, and the less risk averse the administration. These (comparative static) results are formally verified in Appendix 1 . They allow for the important consideration as to why pure RCB may not be for every university and how that depends on the underlying nature of the university and faculty. ${ }^{10}$

\section{Results and Intuition}

\section{When Effort Is Observable}

Begin by taking a step back. Imagine that effort is observed by the university administration so that there is 
no asymmetric information and therefore no hidden effort problem and budget rules can be written directly on effort. The administration still facing the participation constraint would want a desired level of effort by the faculty such that the additional revenue generated from a bit more effort (MR) would equal the additional cost of a bit more effort (MC). ${ }^{11}$ If the former was larger (smaller) then undertake a bit more (less) effort to increase the administration's net budget available for research and teaching. This is the economically efficient level of effort, that is, the level which avoids waste. In this case, the administration can write budget rules on effort directly and then take a dictatorial approach of "take it or leave it". More precisely, a payment mechanism which gives the faculty their reservation level of well-being if they choose the administration's desired efficient level and gives them nothing (or a punishment) otherwise.

The possibility of observing effort will vary with the type of academic institution. The asymmetric information problem and associated hidden effort problem which exists in a large and complex university where the administration has no idea what a state-of-the-art fourth-year physics course looks like does not exist in a two-year college where there are no such courses. Further, the whole issue of the state of the art in research simply does not apply. Possibly, the President/Provost of a community college could devote some research and resources to determine what a good first-year course looks like, largely solve the information problem, and reward the faculty directly on their observed effort. In other words, maybe the President of a college does have the proximity. In rest of the paper, I will assume that effort is not observed by the university administration.

\section{No Uncertainty}

Imagine that effort is not directly observable, but that there is no uncertainty, that is, let $\sigma^{2}=0$. From above, we have $b^{*}=1$ or pure RCB. ${ }^{12}$

\section{Uncertainty but the Faculty is Risk Neu- tral $\left(\sigma^{2}>0, r^{F}=0\right.$, and $\left.r^{U} \geq 0\right)$}

Again $b^{*}=1$ and pure RCB is the solution. These two results provide answers to the first two questions in the introduction. Pure RCB can be the best solution for the administration as it gives them a larger budget and it emerges naturally from a mechanism design analysis. To help with understanding the result, consider a very simple example consistent with Appendix 1.

Imagine the faculty cares only about the education programs and foundational research. These are produced from expenditures on labs, teaching facilities, research and teaching assistants, and the research efforts of faculty members. The administration cares only about applied research suitable for knowledge mobilization. This is produced by the administration directing expenditures on facilities and personnel. Operating revenue is generated by attracting students into the university and keeping them there through faculty efforts in course planning for the enrollment plan, recruitment, and retention, for example, teaching larger classes of more challenging students. This revenue generating effort/time is costly to the faculty, for example, in reduced research effort/time. Neither the effort of the faculty in foundational research nor in revenue generation activities are observed by the administration. Further, if revenues fall the faculty can claim that it is due to some increased recruitment competition from other universities or simply an unexpectedly bad year for applicants, for example, due to a diplomatic dispute.

This is an environment of asymmetric information as the faculty knows their effort level and the administration does not. Monitoring effort is not possible or prohibitively expensive and the observed revenue generated is an imperfect signal of effort due to the inherent uncertainty in the economic environment. As noted, this example is fully compatible with the formal model in the Appendix 1. Appendix 2 allows the administration and the faculty to have shared interests in both research and student programs.

The mechanism design question is: what type of budget rule would the administration wish to employ to solve the incentive problem? As explained above, the level of effort will be wasteful unless $M R=M C$. Here a rational and self-interested faculty will increase their effort until their benefit in increased revenue for their research and student programs expenditures is matched by the increased costs, or to the point where $b M R=M C$. Clearly the only choice for the revenue share, $b$, which solves the administration's incentive problem is pure RCB where $b^{*}=1$. The core of the intuition is that only pure RCB makes the faculty the residual claimant, that is, the claimant of the full benefit of their costly effort.

So far, Deering and Lang's (2017) question as to why 
so many partial RCB implementations, and Curry, Laws, and Strauss's (2013) question about why the pull backs from pure RCB are unanswered. Now, consider a risk averse faculty.

\section{Uncertainty with a Risk Aversion $\left(\sigma^{2}>0\right.$, and $r^{F}>0$, and $r^{U} \geq 0$ )}

From above with $r^{\mathrm{F}}>0,0<b^{*}<1$, that is, partial RCB is best. Why move away from a pure RCB which we have seen is unique in fully handling the hidden effort problem? A problem with pure RCB is that in solving the incentive problem, the faculty holds all of the revenue risk. The payment to the faculty varies with the full swing of uncertain events. The problem for the self-interested administration is that given the risk inherent in the payment and the faculty's risk aversion, the faculty would demand a higher yielding (average) payment for the faculty's acceptance of the deal (participation). It then makes sense for the administration to provide some share of the faculty's overall compensation in fixed payments, to share the risk, and so provide partial insurance against a "bad" year. ${ }^{13}$ Partial RCB provides a balance between the administration's desire to provide the faculty with the incentive to work hard and the administration's desire to insure the faculty in lowering the average payment. One answer then to the third question in the introduction is that partial RCB makes sense if the faculty is risk averse. Partial RCB is the administration sharing the risk in keeping them onside with lower average payments.

The degree of risk aversion is thought to be connected to wealth, with the wealthier apt to be less risk averse. Then this result would provide an explanation as to why larger wealthier faculties with larger endowments, like those at Harvard, are more apt to employ pure RCB.

\section{Conclusion}

The study of university governance should include a consideration of hidden action/moral hazard. Universities, particularly large research-intensive universities, are characterized by very serious and inherent informational asymmetries which makes the governance of universities prone to various challenges, including hidden action. The last forty years has seen a significant evolution in university budgeting with some large research-intensive universities moving from traditional centralized incre- mental budgeting to decentralized responsibility center budgeting. The paper builds a formal mechanism-design model to fit this environment. In the model, a faculty chooses a level of costly effort in generating revenue for the university. The revenue is deployed in research and teaching. The level of faculty effort is not observable by the central administration and the amount of revenue generated from a given level of effort is uncertain. The administration and faculty are assumed risk averse. The model is used to address questions and empirical regularities which exist in the RCB literature.

RCB involves decentralized financial responsibility and university leaders (e.g. a Provost or President) typically believe in their ability to lead. A question then is why give up financial responsibility in adopting RCB? The model shows that there are clear benefits to the administration in adopting RCB. By solving the incentive problem, it leads to a larger operating budget for the university as a whole and for the administration in particular. Only pure RCB fully solves the hidden effort problem through the full alignment of incentives and thereby leads to economically efficient effort and revenue levels.

Given the benefits of RCB were recognized forty years ago why hasn't the adoption of an RCB approach been more widespread? Adjustment costs in transitioning away from an incremental system to RCB are one answer, but the paper provides another answer. Some universities, for example, small teaching-intensive colleges, simply do not face the serious asymmetric information and hidden effort problem which makes the adoption of RCB rational. Further, given that only pure RCB fully solves the incentive problem, why have the adoptions been partial with less than $100 \%$ of the revenue going to the faculties. There have also been some pull backs from pure RCB. It turns out that once the faculty is risk averse, a natural assumption, pure RCB is not the right way to go from the administration's perspective. While it is still true that pure RCB alone fully solves the incentive problem, the university now faces two problems, the incentive problem and the desire to share the risk with the faculty. Impure RCB allows the right trade-off between these different objectives. One of the results is that as the revenue environment becomes more uncertain, we move further away from pure RCB. This means that for a given university, if their revenue environment became more uncertain over time (e.g. increased exchange rate risk and/or a greater reliance on international students), the right approach would be to pull back somewhat from 
pure RCB.

A final empirical regularity is that it is larger, more complex research-intensive universities that are the RCB adopters. As noted above, one would expect that information problems will be less severe in smaller less research-oriented colleges. Another comparative static result is that universities with less risk averse faculties will employ "purer" RCB. Given that wealth is usually associated with lower risk aversion, we have an explanation for the empirical regularity. A Harvard with its large endowments would rationally adopt pure RCB, while small teaching-intensive universities stick with incremental budgeting.

\section{Acknowledgements}

I would like to thank Jonathon Driver, Scott Friedman, Daniel Lang, Glynn Nichols, Douglas Priest, the CJHE reviewers and editor, and the participants of the Canadian Association of Business Officers Conference 2018 for comments and discussions and the Offices of the SFU Provost and the Dean of the Faculty of Arts and Social Sciences for research funding. I would also like to thank the University of Toronto for hospitality while I was working on this paper.

\section{References}

Clark, B. (1998). Creating entrepreneurial universities: organizational pathways of transformation. Oxford, UK: Pergamon.

Cole, J. (2011). The great American university. Bulletin of the American Academy of Arts and Science, 64(3), 27-35.

Curry, J., Laws, A., \& Strauss J. (2013). Responsibility center management: a guide to balancing academic entrepreneurship with fiscal responsibility. Washington, DC: National Association of College and University Business Officers.

Deering, D., \& Lang, D. (2017). Responsibility center budgeting and management 'lite' in university finance: why is RCB/RCM never fully deployed?. Planning for Higher Education, 45(3), 94-109.

Deering, D., \& Sá, C. (2014). Financial management of Canadian universities: adaptative strategies to fiscal constraints. Tertiary Education and Management, 20(3), 207-224.

Holmstrom, B., \& Milgrom, P. (1987). Aggregation and Linearity in the Provision of intertemporal incentives. Econometrica, 55(2), 303-328.

Jaquette, O., Kramer, D., \& Curs B. (2018). Growing the pie? the effect of responsibility center management on tuition revenue. The Journal of Higher Education 89(5), 637-676.

Lang, D. (2002). Responsibility center budgeting and management at the University of Toronto. In D. Priest, W. Becker, D. Hossler, \& P. St. John (Eds.), Incentive-based budgeting systems in public universities (pp. 109-36). Northhampton, MA: Edward Elgar.

Luelfesmann, C., Kessler, A., \& Myers, G. (2015). The architecture of federations: constitutions, bargaining, and moral hazard. Journal of Public Economics, 124, 18-29.

Massy, W. (2016). Reengineering the university: how to be mission centered, market smart, and margin conscious. Baltimore, MD: Johns Hopkins University Press.

Priest, D., Becker, W., Hossler, D., \& St. John, E. (2002). Incentive-based budgeting systems in public universities. Northhampton, MA: Edward Elgar.

Strauss, J., \& Curry, J. (2002). Responsibility center management: lessons from 25 years of decentralized management. Washington, DC: National Association of College and University Business Officers.

Varian, H. (1992), Microeconomic analysis (3rd ed.). New York City, NY: Norton.

Whalen, E. (1991). Responsibility center budgeting: an approach to decentralized management for institutions of higher education. Bloomington, IN: Indiana University Press.

Wilson, J. (2002). The efficiency of responsibility center management within state universities. In D. Priest, W. Becker, D. Hossler, \& E. St. John (Eds.), Incentive-based budgeting systems in public universities (pp. 55-92). Northhampton, MA: Edward Elgar.

Ziskin, M., Hossler, B., Rabourn, D., Cekic, O., \& 
Hwang, Y. (2014). Outcomes based funding: current status, promising practices and emerging trends. Toronto, ON: Higher Education Quality Council of Ontario.

\section{Contact Information}

\author{
Gordon M. Myers \\ gmmyers@sfu.ca
}

\section{Notes}

1 Although, as noted in Curry, Laws, and Strauss (2013) those trained in advocacy (e.g. Deans of Law Schools) would be expected to do well under incremental budgeting. It would also be natural for Deans with a lower opportunity cost of time (e.g. Deans from smaller faculties) to do well. Empirical testing of these conjectures could form the basis of an interesting study of incremental budgeting. Curry, Laws, and Strauss, chapter 1, (2013) has an excellent discussion of strengths and weaknesses of centralized versus decentralized budgeting models in universities.

2 Curry, Laws, and Strauss (2013) label the taxation "participation" and the strategic payouts and cross subsidies "subvention". The specific nature of these taxes and subsidies is important below. It will turn out that precision in this regard is important even in defining "pure RCB". In some RCB universities indirect costs are centralized and managed like overhead costs. While it does not pose issues here, answering the question "why" would make an interesting paper in itself.

3 As noted by Deering and Lang $(2017$, p. 1) much less than half of the world's universities use a version of RCB, but more than half of the top 50 universities in the THE ranking use a version of RCB. Jaquette, Kramer, and Curs (2018) conclude that RCB leads to more revenue for adopters. Another important empirical question would be whether RCB leads adopters to higher academic quality (e.g. possibly measured by rankings).

4 See Varian (1992) for a textbook exposition of asymmetric information. The simple model in this paper is closely related to an example in Varian borrowed from Holmstrom and Milgrom (1987). A closely related use of mechanism design theory to study de- centralization is Luelfesmann, Kessler, and Myers (2015). In many ways this work is a simplification of that paper. Although, that paper is about federal systems of government and assumes risk neutrality for simplicity. Risk aversion is key in this paper.

5 For most Canadian universities the critical revenue source is student tuition and provincial funding driven by getting students in the door and keeping them there. Negotiating an agreement between the administration and faculties on the university's enrollment plan is the first step in making revenue estimates for budgeting. This involves the faculty making and implementing decisions on faculty efforts on recruiting and retaining students, and the acceptance of more and/or larger classes consisting of more challenging students. Other important revenue generating examples would be faculty effort on research grant applications and faculty fund-raising efforts.

6 An often-heard criticism of RCB is that it is all about revenue and universities are about much more than money. A possible response is that RCB is not necessarily about money. It can be about avoiding waste in providing revenue/operating budget for a university in its pursuit of the growth and dissemination of knowledge, in other words, its pursuit of academic excellence. That is captured here by assuming that all revenue is consumed by either the administration or the faculty in paying for research and educational programs and so institutional reputation (as in Clark [1998]). This approach is consistent with the non-profit approach discussed in Appendix G, Massey (2016). The sub-section of this paper below, "Uncertainty with Risk Aversion" sketches a simple example. It should also be noted that while this paper abstracts from issues of equity across faculties, conditional on the same revenue, an RCB can replicate any incrementally driven distribution of budgets across faculties by subvention levels even with a given participation rate.

7 This point may not be clear in the literature, but multiple types of tax instruments are reality. For example, even though the overall share of revenues spent by faculties at the University of Toronto and Simon Fraser University are reasonably similar, b, the share of revenue received by the faculties at Toronto is significantly larger ( 0.9 vs 0.65$)$. What makes these possibly consistent is the $\mathrm{a}$, the fixed payment to the faculty, is significantly larger (negative) at Toronto. 
8 As noted above, budgets are assumed spent on research and student education. It is also assumed in Appendix 1 that the faculty does not value the expenditure of the administration and vice versa. This could be appropriate, for example, if the faculty cared only about research and the administration cared only about the student programs. This assumption is to put RCB in a "worst case", in that, the only value to the administration of sharing revenue $(b>0)$ with the faculty is to motivate revenue generation. However, these assumptions will typically be too strong. In Appendix 2, available upon request, I generalize the model to allow both actors to value the other's expenditures. I show that the paper's qualitative results extend well.

9 Let $\mu$ be the reservation level of well-being for the faculty to be onside. The results below hold for any given $\mu$, high, low, or in between. If you believe faculties have little choice but to be onside, then you believe it is small. If you believe that it requires a lot to keep faculties onside especially with large expenditures at the center, $a<0$, then you believe it is large. Ultimately $\mu$ is about bargaining power and university politics. There is an interesting paper to be written endogenizing $\mu$ in the university context.

10 The results also implies that different $b$ would be optimal for different faculties within a university. While this result is intuitive, to the best of my knowledge, it is not part of any RCB implementation or the RCB literature. The answer as to why may simply be politics, but it is worth further exploration. More than one faculty also allows for a role for the administration to coordinate cooperative insurance against independent risks for the faculties.

11 In terms of the language of the formal model (see Appendix 1) and for the case where there is no uncertainty, the expected budget for the administration is $\tilde{y}(x)-a-b \tilde{y}(x)$ and the net of effort cost expected budget for the faculty is $a+b \tilde{y}(x)$ $c(x)$. Use the participation constraint, $a+b \tilde{y}(x)$ $c(x)=\mu$, to substitute out $a+b \tilde{y}(x)$ in the administration's objective yielding $\tilde{y}(x)-c(x)-\mu$. Then choose effort $(x)$ to maximize the net budget leading to $\tilde{y}^{\prime}\left(x^{*}\right)=c^{\prime}\left(x^{*}\right)$ or the marginal revenue of effort must equal the marginal cost of effort.

12 Pure RCB works, but note when there is no uncertainty, revenue generated becomes a perfect signal of effort and so a take it or leave it offer at the admin- istration's preferred effort/revenue would also work. 13 In the absence of asymmetric information and hidden effort where the budget rule can be written directly on effort, it can be shown that the optimal $b$ is lower than the $b^{*}$ above. In other words, the administration and faculty share the risk and the introduction of hidden effort leads them to reduce the risk sharing by increasing $b$ towards 1 in partially dealing with the incentive problem.

\section{Appendix 1: The Formal Model}

I will keep the analysis simple in buying tractability. ¿? The faculty chooses an action $x \in X$ which generates an outcome given by the production function $y=f(x)$. The action is interpreted as an effort level and the outcome as operating revenue generated by the faculty. As is usual, it is assumed that effort costs are efficiently minimized in the generation of each given revenue level and this is captured by a cost function $c(x)$. We assume that $x \in X$ where $X$ is assumed to be the non-negative real line and the functions $c(x)$ and $f(x)$ are continuously differentiable. We denote the first and second derivatives of a function $f(x)$, by $f^{\prime}(x)$ and $f^{\prime \prime}(x)$ respectively. It is assumed that all revenue $y$ is consumed by the faculty or administration in research and teaching.

For the production process with uncertainty, I assume $\tilde{y}=x+\varepsilon$, where $\varepsilon$ is a normal random variable distributed with a zero mean and a variance of $\sigma^{2}$. This structure for $\varepsilon$ makes $\tilde{y}$ a normal random variable itself, with a variance $\sigma^{2}$ and mean $x$. To allow for the possibility of risk aversion I will assume a simple form of a utility/ objective function to capture the faculty's and administration's preferences over the uncertain revenue.

$$
u(B)=-e^{-r B}
$$

where $e$ is Euler's number, $B$ is budget revenue, and $r$ is a constant absolute risk aversion parameter.

To generate the expected utility, as usual, we sum the utilities across all possible states of the world, weighted by the probability of the state coming into effect. The probability density function is assumed to be $p(\mathrm{~B})$ and is assumed Normal. So expected utility is

$$
E u(B)=-\int_{-\infty}^{\infty} e^{-r B} p(B) d B=-e^{-r\left[B-r \sigma_{B}^{2} / 2\right]}
$$


where $\bar{B}$ is the expected (average) budget. Any positive monotonic transformation of this $\mathrm{Eu}(\mathrm{B})$ would yield the same preferences over outcomes, and $E u(B)$ is increasing in $\bar{B}-r \sigma_{B}^{2} / 2$, so I will use this simple mean-variance form to represent those preferences,

$$
u\left(\bar{B}, \sigma_{B}^{2}\right)=\bar{B}-r \sigma_{B}^{2} / 2
$$

Notice it is increasing in the "yield" (expected revenue) and decreasing in the "risk" $\left(\sigma_{B}^{2}\right)$ and the degree of risk aversion. This approach provides a simple but rigorous rationale for the common "yield versus risk" heuristic. Throughout I will assume that realized revenue (after the uncertainty is resolved), $y$, is observable by both the administration and the faculty but $x$, chosen by the faculty, is not observed by the administration. If effort can only be observed by one party it cannot be used in a budget rule because it is not mutually verifiable. The revenue will be used instead and does provide an imperfect signal of $x$. Let $m(\tilde{y})$ be the expected payment from the administration to the faculty. This $m(\tilde{y})$ is the mechanism designed to deal with the hidden effort. Again, for simplicity, I will restrict it to be a simple linear function or $m(\tilde{y})=a+b \tilde{y}$ where $a$ and $b$ are parameters. As discussed in the main text, if $b=0$ and $a>0$ then we have the incremental budgeting case, if $b=1$ we have a pure RCB, and with $0<b<1$ we have the intermediate case of partial RCB. The faculty uses the revenue available to it through the actual payment $m(y)$ (i.e. its budget) to pay for research and education programs. We also assume that the known (to the faculty) cost of effort enters linearly. Then it's expected well-being is built on $m(\tilde{y})-c(x)$ or using $(U)$,

$$
u\left(E[m(\tilde{y})], \sigma_{m(\tilde{y})}^{2}\right)-c(x)=a+b x-\frac{r^{F} b^{2} \sigma^{2}}{2}-c(x)
$$

Where $E$ is the expectations operator, the mean of the random variable $\tilde{y}$ is $x, b^{2} \sigma^{2}$ is the variance of the budget for the faculty, and $r^{F}$ is the degree of absolute risk aversion for the faculty.

The participation constraint is,

$$
a+b x-c(x)-r^{F} b^{2} \sigma^{2} / 2 \geq \mu(P C)
$$

The incentive compatibility constraint is,

$$
a+b x^{*}-c\left(x^{*}\right)-\frac{r^{F} b^{2} \sigma^{2}}{2} \geq a+b x-c(x)-\frac{r^{F} b^{2} \sigma^{2}}{2} \text { for all } x \in X \text { (ICC) }
$$

where $x^{*}$ is the best effort level by the faculty from the perspective of the administration, in other words, the action the administration wants to induce.

The expected well-being for the administration is built on $\tilde{y}-m(\tilde{y})$ or using $(U)$,

$$
u\left(E[\tilde{y}-m(\tilde{y})], \sigma_{\tilde{y}-m(\tilde{y})}^{2}\right)=(1-b) x-a-\frac{r^{U}(1-b)^{2} \sigma^{2}}{2}
$$

As with the faculty, it is assumed that revenue is used by the administration for research and teaching expenditures.

The university administration chooses the form of payment scheme, that is, the parameters $a$ and $b$, to maximize its objective $\left(\mathrm{O}^{\cup}\right)$ subject to $(\mathrm{PC})$ and (ICC). Given the payment scheme, the faculty then maximizes its objective $\left(O^{F}\right)$ with the choice of $x$.

The faculty doing so would lead to the first-order condition,

$$
b=c^{\prime}(x)(F O C)
$$

As long as the best $x$ is positive, then a solution consistent with (FOC) will ensure the (ICC) is satisfied. This requires that $c^{\prime}(x)>0$ and $c^{\prime \prime}(x)>0$ or a marginal cost which is increasing at an increasing rate and $c^{\prime}(0)<1$.

Ignoring the (ICC) for the moment, and focusing on $\left(O^{\cup}\right)$ and $(\mathrm{PC})$ it is clear that the administration wants the participation constraint to hold with equality or,

$$
b x+a-\frac{r^{F} b^{2} \sigma^{2}}{2}-c(x)=\mu\left(P C^{\prime}\right)
$$

If this were not true, that is, the LHS was greater than the RHS then the administration could decrease parameter $a$, a small amount, while not affecting the faculty's incentive to participate or its optimal choice of $x$ (a does not depend on $\mathrm{x}$ ), and so increasing the administration's budget.

Using (FOC) in $\left(P C^{\prime}\right)$ and solving for a yields,

$$
a=\mu+c(x)+\frac{r^{F}\left(c^{\prime}(x)\right)^{2} \sigma^{2}}{2}-c^{\prime}(x) x\left(P C^{\prime \prime}\right)
$$

Use (FOC) and (PC") to eliminate $b$ and $a$ respectively in $\left(O^{U}\right)$ and simplifying yields

$$
x-\mu-c(x)-\frac{r^{F}\left(c^{\prime}(x)\right)^{2} \sigma^{2}}{2}-\frac{r^{U}\left(1-c^{\prime}(x)\right)^{2} \sigma^{2}}{2}\left(O^{U \prime}\right)
$$

Maximizing this with respect to $x$ allows the administration to determine it's preferred $x^{*}$ and thereby its pre- 
ferred choice for $b$,

$$
c^{\prime}\left(x^{*}\right)=\frac{1+r^{U} c^{\prime \prime}\left(x^{*}\right) \sigma^{2}}{1+\left(r^{F}+r^{U}\right) c^{\prime \prime}\left(x^{*}\right) \sigma^{2}}=b^{*} \quad(*)
$$

To allow for a closed-form solution, I assume $c(x)=c x^{2} / 2$ so that $c^{\prime}(x)=c x$ and $c^{\prime \prime}(x)=c$. This is then the equation at the end of the "An Exposition of the Model" section above. 